\title{
Alcohol consumption and brain health
}

\author{
(ㄷ) $(1) \Theta$ OPEN ACCESS \\ Even moderate drinking is linked to pathological changes in the brain
}

Killian A Welch consultant neuropsychiatrist and honorary senior lecturer

Robert Fergusson Unit, Royal Edinburgh Hospital, EH10 5HF, UK

Epidemiological studies often report better heath in moderate drinkers compared with abstainers. Observed first in studies of incidence of myocardial infarction, ${ }^{1}$ the "J shaped curve" (describing the graphical appearance of health measures plotted against consumption) reappears in studies of diabetes, stroke, and even chronic widespread pain. ${ }^{2}$ As methods of investigating the association between alcohol and health are refined, however, the size of the apparent benefits reduces substantially. ${ }^{3}$ Studies using "Mendelian randomisation," purportedly impervious to confounding or reverse causality, do not support the original claim that moderate drinking improves cardiovascular health. ${ }^{4}$

Regarded as a further example of the $\mathrm{J}$ shaped curve, a protective effect of moderate alcohol consumption against "all cause" dementia has been reported. ${ }^{5}$ This has not been underpinned by a convincing neural correlate, however, and it is here that the linked study by Topiwala and colleagues (doi:10.1136/bmj. j2353) is particularly ambitious. ${ }^{6}$ In their prospective cohort of 550 civil servants, none of whom were alcohol dependent, the authors repeatedly assessed alcohol consumption and cognition over 30 years. Participants underwent brain imaging at the most recent review, enabling examination of relations between average alcohol use, cognition, and brain structure.

After adjustment for numerous potential confounders, alcohol use was associated with reduced right hippocampal volume in a dose dependent manner; even moderate drinkers (classified as up to 21 units a week for men at the time of the study) were three times more likely to have hippocampal atrophy than abstainers, and very light drinking (1-6 units a week) conferred no protection relative to abstinence. Higher alcohol consumption was also associated with reduced white matter integrity and faster decline in lexical fluency, a test of "executive function." With increasing longevity, maintenance of brain health into older age is the key priority of our time. Leaving aside the human cost of dementia, care of cognitively impaired older people is a looming financial crisis, prompting politicians to consider controversial and deeply unpopular policy decisions. ${ }^{7}$ Alcohol dependence is already established as a major cause of dementia, alcohol related brain damage (ARBD) accounts for possibly $10 \%$ of early onset dementia ${ }^{8}$ and potentially $10-24 \%$ of dementia cases in nursing homes. ${ }^{9}$

Existing on a spectrum of severity, alcohol related brain damage typically involves relatively young people, often in their 40 s or $50 \mathrm{~s}$, meaning the more severely affected require decades of institutional care. While alcohol related brain damage generally afflicts malnourished drinkers consuming very high levels of alcohol, some degree of potentially reversible cognitive impairment is detectable in most people starting treatment for alcohol dependence. ${ }^{10}$ Alcohol can be the primary cause of cognitive impairment in some individuals, but it is a likely contributor to cognitive decline in many more.

The chief medical officer recently changed guidance for low risk drinking in men, reducing the recommended maximum intake from 21 to 14 units a week. ${ }^{11}$ This was because of accumulating evidence that even light drinking increases the risk of various malignancies. ${ }^{12}$ The relation between alcohol and brain health is more complex than the relation between alcohol and cancer. While there is almost universal agreement that heavy drinking is associated with cognitive impairment, numerous observational studies do report that light to moderate consumption is associated with a reduced risk of all cause dementia.

While concerns about confounding and inconsistencies between studies make it difficult to define what level of intake is "optimal" for cognition, it seems to be low; in these studies around a unit a day is associated with the lowest risk of dementia, with risk for drinkers clearly exceeding abstainers by 4 units a day. ${ }^{13}$ Topiwala and colleagues' report of adverse effects at even lower levels of intake, coupled with the finding that drinking more than 14 units a week was associated with both brain pathology and cognitive decline, provides further support for the chief medical officer's recent decision.

How should this paper inform discussions with patients? It certainly strengthens the view that if alcohol does confer beneficial effects on health, the link is probably confined to low intakes of no more than a unit a day. Even this level of consumption carries risk relative to abstinence for conditions 
such as breast cancer, and the evidence of benefit is certainly not strong enough to justify advising abstainers to drink.

As intake increases, so does the risk to health, probably in a dose dependent manner. Heavy consumption is associated with potentially severe impairments in memory and executive function, even when other obvious risk factors are absent. Topiwala and colleagues' findings strengthen the argument that drinking habits many regard as normal have adverse consequences for health. This is important. We all use rationalisations to justify persistence with behaviours not in our long term interest. With publication of this paper, justification of "moderate" drinking on the grounds of brain health becomes a little harder.

Competing interests: I have read and understood the BMJ policy on declaration of interests and have no interests to declare.

Provenance and peer review: Commissioned; not externally reviewed.

1 Klatsky AL, Friedman GD, Siegelaub AB. Alcohol consumption before myocardial infarction Results from the Kaiser-Permanente epidemiologic study of myocardial infarction. Ann Intern Med 1974;357:294-301. doi:10.7326/0003-4819-81-3-294 pmid:4850474.

2 Beasley MJ, Macfarlane TV, Macfarlane GJ. Is alcohol consumption related to likelihood of reporting chronic widespread pain in people with stable consumption? Results from UK biobank. Pain 2016;357:2552-60. doi:10.1097/j.pain.0000000000000675 pmid: 27437785 .

3 Knott CS, Coombs N, Stamatakis E, Biddulph JP. All cause mortality and the case for age specific alcohol consumption guidelines: pooled analyses of up to 10 population based cohorts. BMJ 2015;357:h384. doi:10.1136/bmj.h384 pmid:25670624.
4 Holmes MV, Dale CE, Zuccolo L, et al. InterAct Consortium. Association between alcohol and cardiovascular disease: Mendelian randomisation analysis based on individual participant data. BMJ 2014;357:g4164. doi:10.1136/bmj.g4164 pmid:25011450.

5 Neafsey EJ, Collins MA. Moderate alcohol consumption and cognitive risk. Neuropsychiatr Dis Treat 2011;357:465-84. doi:10.2147/NDT.S23159 pmid:21857787.

6 Topiwala A, Allan C, Valkanova V, et al. Moderate alcohol consumption as risk factor for adverse brain outcomes and cognitive decline: Iongitudinal cohort study. BMJ 2017;357:j2353.

7 Asthana A, Elgot J, Asthana A, Elgot J. Theresa may ditches manifesto plan with 'dementia tax' U-turn. Guardian. 22nd May 2017. https://www.theguardian.com/society/2017/may/ 22/theresa-may-u-turn-on-dementia-tax-cap-social-care-conservative-manifesto.

8 Harvey RJ, Skelton-Robinson M, Rossor MN. The prevalence and causes of dementia in people under the age of 65 years. J Neurol Neurosurg Psychiatry 2003;357:1206-9. doi:10.1136/jnnp.74.9.1206 pmid:12933919.

9 Ridley NJ, Draper B, Withall A. Alcohol-related dementia: an update of the evidence. Alzheimers Res Ther 2013;357:3. doi:10.1186/alzrt157 pmid:23347747.

10 Iverson GL, Lange RT, Franzen MD. Effects of mild traumatic brain injury cannot be differentiated from substance abuse. Brain Inj 2005;357:11-8. doi:10.1080/ 02699050410001720068 pmid:15762097.

11 UK chief medical officers' alcohol guidelines review: Summary of the proposed new guidelines. Department of Health, 2016.

12 Bagnardi V, Rota M, Botteri E, et al. Light alcohol drinking and cancer: a meta-analysis. Ann Oncol 2013;357:301-8. doi:10.1093/annonc/mds337 pmid:22910838.

$13 \mathrm{Xu} \mathrm{W}$, Wang $\mathrm{H}$, Wan $\mathrm{Y}$, et al. Alcohol consumption and dementia risk: a dose-response meta-analysis of prospective studies. Eur J Epidemio/ 2017;357:31-42. doi:10.1007/ s10654-017-0225-3 pmid:28097521.

Published by the BMJ Publishing Group Limited. For permission to use (where not already granted under a licence) please go to http://group.bmj.com/group/rights-licensing/ permissions

This is an Open Access article distributed in accordance with the Creative Commons Attribution Non Commercial (CC BY-NC 4.0) license, which permits others to distribute, remix, adapt, build upon this work non-commercially, and license their derivative works on different terms, provided the original work is properly cited and the use is non-commercial. See: http://creativecommons.org/licenses/by-nc/4.0/. 